\title{
Acting on Adherence: Better Sooner
} than Later

The famous saying of former US surgeon general C Everett Koop_- "Drugs don't work in patients who don't take them"1recalls a sine qua non principle of medication: adherence is the prerequisite of effectiveness. As medication experts practising pharmaceutical care, pharmacists are central to improving medication adherence. In the 2000s, medication non-adherence has been associated with an annual loss of $\$ 7$ billion in Canada, ${ }^{2}$ underscoring the need for pharmacy practitioners to take action, both to promote positive pharmacotherapy outcomes for the patient and to support the sustainability of the health care system. Pharmacist-led initiatives and research on adherence are increasing steadily across Canada, including the CPATCH project (Community Pharmacists Assisting in Total Cardiovascular Health; http://cpatch.usask.ca/cpatch/index.php), led by a group from the University of Saskatchewan and the Royal University Hospital, ${ }^{3}$ and the Mouvement pour l'adhésion au traitement, led by the Université Laval (www.adhesionauxtraitements.org/). 


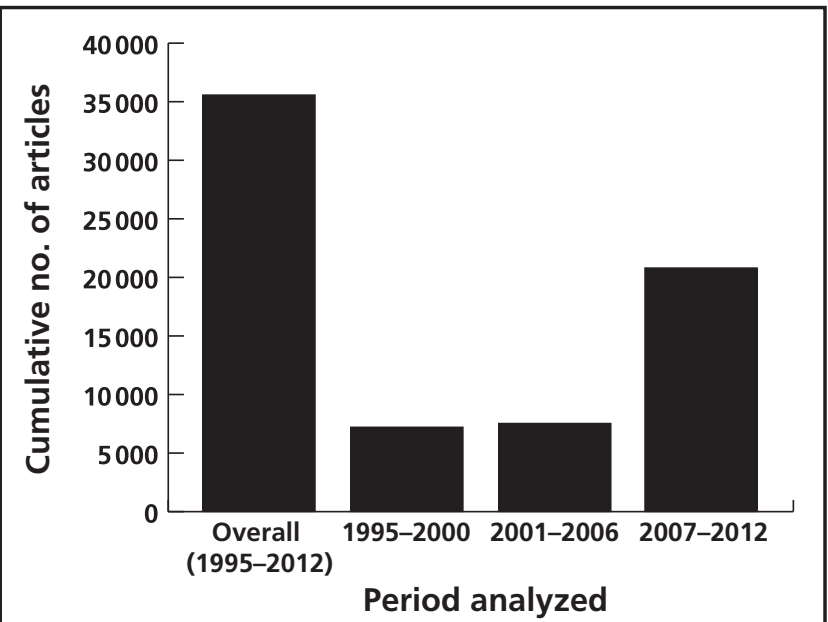

Figure 1. Number of articles on adherence to medication published between 1995 and 2012, overall and by 6-year periods. These data show an increase in research on the subject over this period. Data retrieved from Web of Knowledge (Thomson Reuters) on September 30, 2012.

There are several determinants of adherence, many of which pharmacists can influence, notably by educating patients about the effects of medications on health outcomes and quality of life and by dispelling myths and fears. However, adherence is also tied to care at the various levels of the health care system (i.e., across the continuum of care). A patient's transition from the hospital to the community or a long-term care home (and vice versa) represents a sensitive moment, where slip-ups may occur, breaking seamless and optimal care. Given that hospitals usually deal with complex situations in which patients may be started on multiple long-term medications simultaneously, the work of hospital pharmacists could be a critical reference point where adherence can first be tackled. Developing this role would require several elements, notably, creating an environment that offers opportunities for increasing pharmacists' expertise in complex medication therapy (i.e., specialization) and increasing their involvement in medication counselling at the hospital; studying the hospital's selfmedication program to better support the role of pharmacists within an expanded interdisciplinary environment; and/or facilitating collaboration between hospital and community pharmacists (e.g., through better communication systems). Additionally, it would be beneficial to increase initiatives and research or pilot projects on adherence (especially those involving partnership between the hospital and the community) to identify gaps in practice along the continuum of care. An important target group in these studies could be patients with heart disease, since these patients are usually taking multiple medications to reduce morbidity and mortality ${ }^{4}$ and cardiovascular diseases represent one of the most important causes of hospital admission and death in Canada.,5

Currently, many patients get "lost" in the transition from hospital to community and vice versa (through fragmentation of

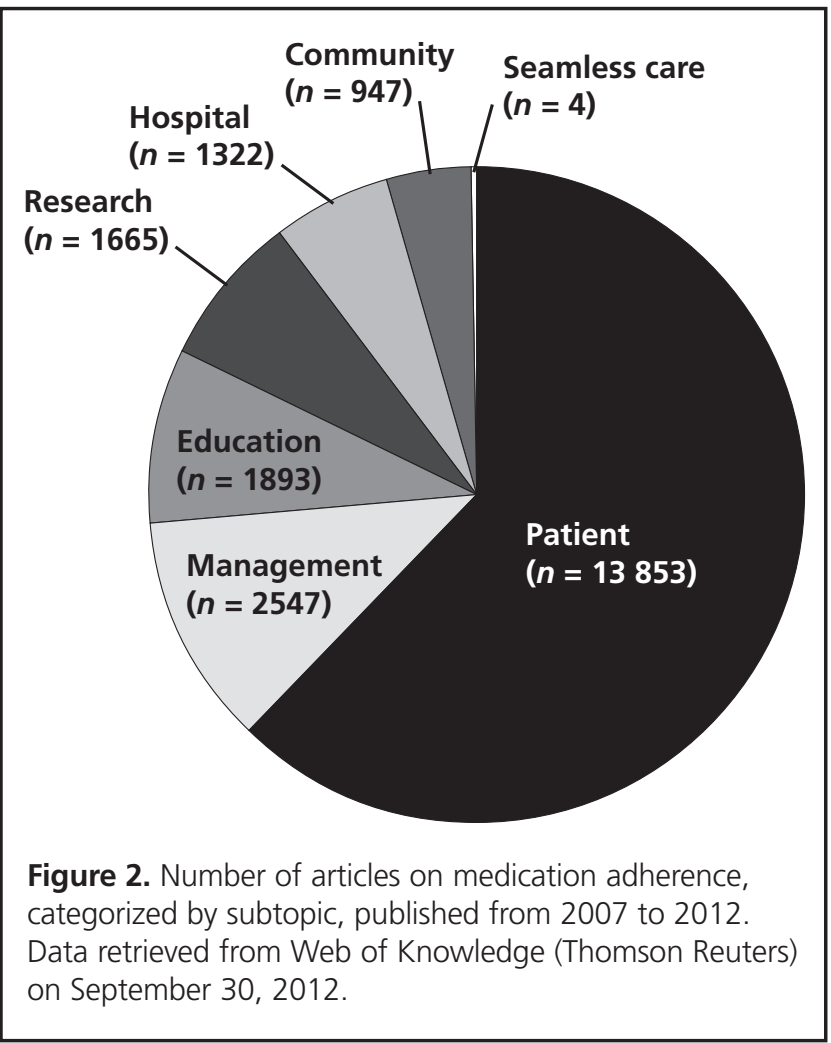

care). This situation challenges us to ensure the implementation and maintenance of adherence but also begs for meaningful changes in the system to meet patients' needs and expectations and to increase collaboration among health care professionals at the different levels of care. Such change can be favoured by research and pilot projects in seamless care, an area that remains poorly explored. Data presented by the Web of Knowledge indicate that, although medication adherence has been gaining importance since 2007 in terms of the number of publications (Fig. 1), only 4 of 20818 articles published between 2007 and 2012 focused on seamless care and adherence (Fig. 2). ${ }^{6}$ At the same time, the first report of the Health Care Innovation Working Group underlined "that [Canadian] patients and their families are rightfully demanding timely care that is seamless."

Drugs represent a large proportion of our health care system's expenditures, growing by about $6 \%$ every 10 years. ${ }^{8}$ With this growth, it becomes critical to improve achievement of desired outcomes. ${ }^{8}$ One solution is to emphasize adherence as a third element of the medication triad, alongside efficacy and safety. As pharmacy practice moves toward patient-centred care, medication adherence becomes another way for hospital and community pharmacists to work together as they watch over the life and health of their patients.

\section{References}

1. The importance of patient adherence to medication therapy. In: HealthFlock [blog]. Atlanta (GA): Atlanta Journal-Constitution; 2011 [cited 2012 Sep 30]. Available from: http://blogs.ajc.com/health-flock/2011/08/03/the-importanceof-patient-adherence-to-medication-therapy/ 
2. Samson C. L'adhésion au traitement : l'art de prendre sa pilule. Québec (QC) : La Presse, ltée; 2010 [cited 2013 Jul 12]. Available from: www.lapresse.ca/ le-soleil/actualites/sante/201005/19/01-4282058-ladhesion-aux-traitementslart-de-prendre-sa-pilule.php

3. Evans CD, Eurich DT, Taylor JG, Remillard AJ, Shevchuk YM, Blackburn DF. A pragmatic cluster randomized trial evaluating the impact of a community pharmacy intervention on statin adherence: rationale and design of the Community Pharmacy Assisting in Total Cardiovascular Health (CPATCH) study. Trials. 2010;11:76.

4. Newby LK, Dobesh PP, Ashen D. Key strategies to maximize adherence to secondary prevention therapies for coronary artery disease. New York (NY): Medscape; 2011 [cited 2012 Sep 30]. Available from: www.medscape.org/ viewarticle/736196. Registration required to access content.

5. Statistics. Ottawa (ON): Heart and Stroke Foundation of Canada; 2013 [cited 2012 Sep 30]. Available from: www.heartandstroke.com/site/ c.ikIQLcMWJtE/b.3483991/

6. Web of knowledge. Philadelphia (PA): Thomson Reuters; 2012 [cited 2012 Sep 30]. Available from: http://apps.webofknowledge.com.cyber.usask.ca/. Registration required to access content.
7. From innovation to action: the first report of the Health Care Innovation Working Group. Ottawa (ON): Council of the Federation; 2012 [cited 2012 Sep 30]. Available from: www.councilofthefederation.ca/pdfs/Health\%20Innovation \%20Report-E-WEB.pdf

8. Lynas K. Drug expenditures on the rise. Can Pharm J. 2009;142(3):116-7.

Silva Vujanovic, BSP

College of Pharmacy and Nutrition

University of Saskatchewan

Saskatoon, Saskatchewan

Competing interests: None declared.

Acknowledgements: Thanks are extended to Tim Veregin, Director of Pharmacy at Bruyère Continuing Care, Ottawa, Ontario, and to David F Blackburn, Associate Professor of Pharmacy and Research Chair in Patient Adherence at the University of Saskatchewan, Saskatoon, Saskatchewan, for useful comments on a draft version of this letter.

\title{
几 Canadian Society of Hospital Pharmacists Société canadienne des pharmaciens d'hôpitaux
}

\author{
Membership Year 2013/2014 \\ (July 1, 2013 - June 30, 2014)
}

Are you a member of the Canadian Society of Hospital Pharmacists?

CSHP has celebrated 66 years of inspiration and leadership among a rapidly growing network of over 3000 pharmacy colleagues. As a member of CSHP, you will have access to resources and opportunities that will enhance your career and help impact the direction of healthcare in Canada. Your participation in CSHP 2015, an initiative challenging all pharmacists to improve patient medication outcomes and safety through advancing pharmacy practice excellence by the year 2015 , is a prime example.

We invite you to reap the benefits of an affordable membership with CSHP. For more information, please visit www.cshp.ca.

Membership Enquiries: Please contact Membership Services

Tel.: (613) 736-9733 Ext. 222 Fax: (613) 736-5660 Email: $\underline{\text { membershipservices@cshp.ca }}$ 